\title{
Children's attitudes towards animals are similar across suburban, exurban, and rural areas
}

\author{
Stephanie G. Schuttler ${ }^{\text {Corresp., } 1}$, Kathryn Stevenson ${ }^{2}$, Roland Kays ${ }^{1,3}$, Robert R. Dunn ${ }^{4,5}$ \\ 1 North Carolina Museum of Natural Sciences, Raleigh, North Carolina, United States \\ 2 Department of Parks, Recreation and Tourism Management, North Carolina State University, Raleigh, North Carolina, United States \\ 3 Department of Forestry \& Environmental Resources, North Carolina State University, Raleigh, North Carolina, United States \\ 4 Department of Applied Ecology, North Carolina State University, Raleigh, North Carolina, United States \\ ${ }^{5}$ Center for Macroecology, Evolution and Climate, Natural History Museum of Denmark, University of Copenhagen, Copenhagen, Denmark \\ Corresponding Author: Stephanie G. Schuttler \\ Email address: stephanie.schuttler@naturalsciences.org
}

The decline in the number of hours Americans spend outdoors, exacerbated by urbanization, has affected people's familiarity with local wildlife. This is concerning to conservationists, as people tend to care about and invest in what they know. Children represent the future supporters of conservation, such that their knowledge about and feelings towards wildlife have the potential to influence conservation for many years to come. Yet, little research has been conducted on children's attitudes towards wildlife, particularly across zones of urbanization. We surveyed 2,759 4-8th grade children across 22 suburban, exurban, and rural schools in North Carolina to determine their attitudes toward local, domestic, and exotic animals. We predicted that children who live in rural or exurban areas, where they may have more direct access to more wildlife species, would list more local animals as 'liked' and fewer as 'scary' compared to children in suburban areas. However, children, regardless of where they lived, provided mostly non-native mammals for open-ended responses, and were more likely to list local animals as scary than as liked. We found urbanization to have little effect on the number of local animals children listed, and the rankings of 'liked' animals were correlated across zones of urbanization. Promising for conservation was that half of the top 'liked' animals included species or taxonomic groups containing threatened or endangered species. Despite different levels of urbanization, children had either an unfamiliarity with and/or low preference for local animals, suggesting that a disconnect between children and local biodiversity is already well-established, even in more rural areas where many wildlife species can be found. 
1 Children's attitudes towards animals are similar across suburban, exurban, and rural areas

3 Authors: Stephanie G. Schuttler ${ }^{1}$, Kathryn Stevenson ${ }^{2}$, Roland Kays ${ }^{1,3}$, Robert R. Dunn ${ }^{4,5}$

$4{ }^{1}$ North Carolina Museum of Natural Sciences, Raleigh, NC USA

5 2Department of Parks, Recreation and Tourism Management, North Carolina State University,

6 Raleigh, NC USA

$7 \quad 3$ Department of Forestry \& Environmental Resources, North Carolina State University, Raleigh,

8 NC USA

$9{ }^{4}$ Department of Applied Ecology, North Carolina State University, Raleigh, NC USA

$10{ }^{5}$ Center for Macroecology, Evolution and Climate, Natural History Museum of Denmark,

11 University of Copenhagen, Copenhagen, Denmark

13 Corresponding author:

14 Stephanie Schuttler

15 North Carolina Museum of Natural Sciences

1611 West Jones Street

17 Raleigh, NC 27601

18 Stephanie.schuttler@gmail.com

19 Orcid ID: 0000-0001-9523-4448

21 Short title: Youth attitudes towards animals 


\section{Abstract}

The decline in the number of hours Americans spend outdoors, exacerbated by

24 urbanization, has affected people's familiarity with local wildlife. This is concerning to conservationists, as people tend to care about and invest in what they know. Children represent the future supporters of conservation, such that their knowledge about and feelings towards wildlife have the potential to influence conservation for many years to come. Yet, little research has been conducted on children's attitudes towards wildlife, particularly across zones of urbanization. We surveyed $2,7594-8^{\text {th }}$ grade children across 22 suburban, exurban, and rural schools in North Carolina to determine their attitudes toward local, domestic, and exotic animals. We predicted that children who live in rural or exurban areas, where they may have more direct access to more wildlife species, would list more local animals as 'liked' and fewer as 'scary' compared to children in suburban areas. However, children, regardless of where they lived, provided mostly non-native mammals for open-ended responses, and were more likely to list local animals as scary than as liked. We found urbanization to have little effect on the number of local animals children listed, and the rankings of 'liked' animals were correlated across zones of urbanization. Promising for conservation was that half of the top 'liked' animals included species or taxonomic groups containing threatened or endangered species. Despite different levels of urbanization, children had either an unfamiliarity with and/or low preference for local animals, suggesting that a disconnect between children and local biodiversity is already well-established, even in more rural areas where many wildlife species can be found. 
One of the biggest threats to the conservation of biodiversity is the "extinction of

experience," a term used to describe the largescale decline of people's time spent in nature and

the diverse experiences time in nature entails (Pyle 1978). Individuals who have had more

experiences are more likely to have pro-environmental attitudes, especially when those experiences occurred during childhood (Soga \& Gaston 2016). Today, children spend much less time outdoors than the generations before them, and fewer people live in rural areas surrounded by large, natural spaces (Kellert et al. 2017). As people spend more time indoors and have less access to natural areas in their daily lives, their familiarity with and perspectives towards local wildlife will likely change.

While many conservation biologists focus on challenges associated with the health of an ecosystem such as habitat loss, declines in native biodiversity, increases in invasive species, and pollution (Aronson et al. 2014; Dirzo et al. 2014), challenges that relate to societal perceptions are equally important. These perceptions of nature set the template that influences the future willingness of the public to invest in the conservation of nature. For example, the intolerance of wildlife, perceived threats or nuisances, and a lack of funding and public support for policy can all thwart otherwise-successful conservation efforts (Brook et al. 2003; Inskip \& Zimmermann 2009). It is especially pertinent to study the perceptions children have on wildlife, as they are the future stakeholders, and interventions made during childhood are more likely to be successful when values are still forming (Feinsinger 1987; Manfredo et al. 2017). Children tend to favor what have been termed "loveable animals," which includes domestic pets and large, charismatic megafauna (Bjerke et al. 1998; Borgi \& Cirulli 2015; 
66

67

et al. 2017; Loss et al. 2013). Many species of charismatic megafauna are of conservation concern, such as the case for pandas, great apes, big cats, elephants, and rhinoceros. Indeed, to the extent that megafauna are often not only threatened, but also conservation targets (Dietz et al. 1994; Smith \& Sutton 2008), the fondness of children for "loveable animals" may actually lead to a fondness for species of conservation concern. One recent study even showed potential for children to align more closely with conservationists' prioritization of species attributes (Frew et al. 2016) than adults in a similarly designed study (Meuser et al. 2009). Yet, if children only value charismatic megafauna and pets, they may lose connections to local species and hence a willingness to conserve species nearby. One arbiter of whether children value local species may be their experience with those species (Ballouard et al. 2011; Lindemann-Matthies 2005; Schlegel \& Rupf 2010). Given that more children live in urban or urbanized landscapes than in previous generations, and that urbanization impacts the richness and diversity of wildlife communities (McKinney 2008), a "pigeon paradox" (Dunn et al. 2006) may occur, where people will be motivated to protect species they are most familiar with, but in places where those species tend to be common and pest species. Under this scenario, people will primarily experience nature through these common and even invasive, urban species (which only rarely need conservation attention) or virtually through the Internet and television (where the focus is often on exotic megafauna). Whether this is the case in practice is unclear. Children in some regions have been shown to prefer species they never experience in real life (Ballouard et al. 2011) and struggle to identify local wildlife compared to exotic species popularized in the media and even imaginary Poke'mon characters (Ballouard et al. 2011; 
87 Balmford et al. 2002; Genovart et al. 2013). Whether the preferences of children for particular

88 species varies with the degree of urbanization of their home place is unknown.

Additionally, modern lifestyle can even play a role in children viewing the outdoors negatively. One study found that children who had a stronger desire for modern comforts and manicured parks, had a dislike of wild, more natural spaces (Bixler \& Floyd 1997), whereas another found that some children in the UK even viewed wooded areas as "scary places" (Milligan \& Bingley 2007). With an increase in modern lifestyle, children today may be viewing nature as more scary, which could carryover to wild animals as well. For example, urban children in Norway viewed wolves and eagles as significantly more scary and dangerous than rural children did (Bjerke et al. 1998). We investigated the preferences of 9-14 year old children towards wildlife, specifically animals, across different levels of urbanization in North Carolina, USA. We were interested in which animals children considered to be positive (i.e., liked), which were viewed negatively (i.e., scary) and whether these rankings were associated with how likely the children were to be able to experience these animals in their everyday lives (as a function of whether they were domestic, local, or exotic animals). Our objectives were to (1) identify the animals children recalled, (2) determine if children listed different animals for those they liked and those they considered scary, (3) categorize liked or scary animals as local, domestic, or exotic, and (4) understand how these categorizations varied across the level of urbanization (suburban, exurban, or rural) of the children' school and other demographic and socioeconomic factors. Due to presumed increased opportunities for encounters with animals in rural and exurban areas (Zhang et al. 2014), we predicted that children from these schools would include more 
109 local species for liked animals and fewer for scary than children from suburban schools. In

110 zones of higher urbanization (i.e. suburban areas), we predicted that children would favor non-

111 native animals, as we expected their relationship with wildlife to be primarily based on virtual

112 encounters, zoos, or pets.

113

114 Materials and Methods

115 Sampling Plan

116 We surveyed $4^{\text {th }}, 6^{\text {th }}, 7^{\text {th }}$, and $8^{\text {th }}$ grade children in classrooms of teachers participating in

117 the eMammal citizen science camera trap program (eMammal.org) in North Carolina from

118 2014-2017 (Schuttler et al. 2017; Schuttler et al. 2018). North Carolina teachers were recruited

119 through program advertisements, direct emailing, word of mouth, and through presentations at

120 conferences. As this research was part of a study on the potential impacts of eMammal citizen

121 science in the classroom, we also invited teachers from different schools within the same

122 school districts to participate in the surveys, even if they would not be participating in the

123 eMammal program. Surveys for this study were conducted prior to any mention of or

124 implementation of the eMammal program. We asked participating teachers to include their

125 children in the study by administering surveys in their classrooms. Although teachers were self-

126 selected into this study, which may relate to their perceptions of wildlife, children were

127 included in the study based on their assignments to teachers, which relied on factors not

128 related to wildlife perceptions or experiences in nature.

129

130

Survey Design and Data Collection

Peer) reviewing PDF | (2018:12:33903:2:0:NEW 28 May 2019) 
132 found most scary, and to rank their top five favorite mammals from a list of 20. Children were

133 asked the free list question first, but could see the rank question. As children do not think of

134 animals based on biologists' taxonomic classifications, we named species or groups of species

135 at the taxonomic level they would be able to identify (Ballouard et al. 2011). For the list of 20

136 mammals, we tried to pair local animals with exotic animals that children would know. While

137 this included a list of more charismatic, exotic species compared to local ones, we did not

138 expect local species to outrank charismatic, exotic species. Rather, we were interested to see

139 where local species ranked amongst those that are well-known and liked by children and to

140 determine if there are differences in rankings between children from different levels of

141 urbanization. The list included 11 mammals local to North Carolina and 9 exotic mammals

142 (local: bobcat, coyote, raccoon, skunk, deer, rabbit, opossum, fox, bear, squirrel, bat; exotic:

143 kangaroo, zebra, lion, panda, rhinoceros, monkey, wolf, whale, hedgehog). We defined local

144 species in the context of children' ability to see a species in their daily lives and therefore

145 included non-domestic, non-marine species (all schools were inland) with current range in

146 North Carolina. Further, while red wolves do exist in North Carolina, they are restricted to a

147 small range far from the schools surveyed in this study, so we categorized wolves as exotic.

148 Survey questions are in Supporting Fig 1.

149 During year one, we asked teachers to administer surveys in classrooms on paper. We

150 asked children clarifying questions to assess how well they understood survey questions. Some

151 children misunderstood how to rank species (e.g. they gave all species a 1 or 5) and in

152 subsequent years, we instructed teachers to verbally explain this question when administering 
153 surveys. Children sometimes asked questions about what was considered an animal and in

154 subsequent surveys we instructed teachers to tell children to include only non-human, extant

155 animals. We found no difficulties for children in answering any other questions and therefore

156 continued to use the survey data from all years. After the first year, we moved the survey

157 online using Qualtrics, and provided teachers with a script to read before administering the

158 survey. We included the year as a random effect in analyses to test for potential differences

159 and removed any responses in which children clearly misinterpreted the question or had

160 incomplete responses.

161 Children self-reported demographic information including race (Asian, African American,

162 Caucasian, Hispanic or Latino, Native American, and other), gender, and grade. In 2015, we

163 started asking children whether they or anyone in their family hunted as hunting can influence

164 children' exposure to, and knowledge of local biodiversity (Peterson et al. 2017). We also

165 collected school-level socioeconomic data by calculating the percentage of children eligible for

166 free and reduced lunches from the National Center for Education Statistics

167 (https://nces.ed.gov). We distributed permission slips with information about the study to

168 parents/guardians for schools that required written consent. For schools that did not require

169 written consent, we distributed informational sheets for parents/guardians to opt their children

170 out of the study. Survey methods were reviewed and approved by the North Carolina State

171 University Institutional Review 159 Board for the Protection of Human Subjects (application

172 \#4166).

173

174 Data analysis 
We coded animals children listed first to their taxonomic class, with the following

176 modifications: fish species were all grouped into one class (fish) and invertebrates were

177 grouped into marine and terrestrial invertebrates. We placed humans, animals that are not real

178 (mythical animals), extinct animals, and the written response "none" into separate categories.

179 We classified each extant, non-human species as local, domestic or exotic (species were

180 assigned one category only). Domestic species included livestock: cows, horses or ponies,

181 sheep, goats, swine, and poultry (chicken and turkey, https://www.nal.usda.gov/animals-and-

182 livestock). Domestic pets included dogs and cats, and the categories of specialty and exotic

183 animals listed by the American Veterinary Medicine Foundation (fish, ferrets, rabbits, hamsters,

184 guinea pigs, gerbils, turtles, snakes, lizards). We used the same criteria described above to

185 identify species as local (i.e., children might have an opportunity to see locally). Some responses

186 children listed were generic to geographic location (e.g. bears, birds) and could have referred to

187 both local and exotic species. We classified these species as local as they fit the definition for

188 local, and children could have the opportunity to view such species, but may not know the

189 specific species name. Any species that did not meet the definition for local or domestic was

190 considered exotic.

191 Schools were considered suburban, exurban, or rural based on the Silvis housing density

192 categories: suburban (147.048-1000 houses $\left./ \mathrm{km}^{2}\right)$, exurban (12.64-147.047 houses/km²), rural

193 (0.51-12.63 houses $\left./ \mathrm{km}^{2}\right)$ (Hammer et al. 2004). All analyses were conducted in the Program R

194 (R Development Core Team,2011). We tested for significant differences across the variances

195 and means of local animals for liked, scary, and ranked responses using the Fligner-Killeen and

196 the Kruskal-Wallis tests respectively. For significant results, we used a Tukey and Kramer 
197 (Nemenyi) test to determine which treatments were significantly different from each other. For

198 the question on how children ranked species, we also conducted a Spearman rank correlation

199 test between the overall rank of species according to each level of urbanization and applied a

200 Bonferroni correction for multiple tests. Before running models, we tested for correlations

201 between categorical covariates using Goodman and Kruskal's tau with the package

202 GoodmanKruskal, and removed the covariate whether a student's family hunts as this was

203 correlated with hunting $(>0.50)$.

204

We ran three generalized linear mixed models with family set as Poisson using package

205

Ime4. The response variables for the three models included the (1) number of local animals

206

children free listed as those they liked, (2) the number of local animals children free listed as

207

scary, and (3) the number of local animals included in children's top five when asked to rank

208

animals (0-5, Table 1). Before running models, we removed responses where the children did

209

not specify a gender as there were very few surveys with no response to this question $(n=23)$,

210

and this was largely due to children running out of time (other responses were incomplete). In

211 initial models, race was not a significant factor. Due to the small sample size of some races, we

212 collapsed all races into white (children who only checked Caucasian) and non-white categories

213 (children who checked at least one non-white race category) for final models. Random effects

214 included the school the student attended and year the survey was taken, while fixed effects

215 included the following: gender, race, housing development, the percentage of free or reduced

216 lunches, and hunting (Table 1). For all models, random effects estimates were $<0.001$ and we

217 therefore proceeded with final models run as generalized linear models in the package MuMIn

218 in R. We ran all combinations of all covariates and considered top models to be those within 2 
219 AIC points (Burnham \& Anderson 2002). We determined coefficient values and significant

220 covariates from the top model or model averaged if there was more than one.

221

222 Results

223

We implemented surveys in 1 private and 21 public schools in North Carolina. We

224 included 15 suburban, six exurban, and one rural school. Some schools were sampled multiple

225 years, but with different children. In total, across these schools we collected data from 2,759

226 children (Table 2). Teacher participation was distributed across schools located in areas ranging

227 from 8.52 to 482.43 houses $/ \mathrm{km}^{2}$. We sampled fewer rural and exurban schools, in line with the

228 demographics of the state in which more students and schools are in urbanized areas. Our

229 dataset included children from all races and the entire range of socioeconomic status (0 to

$230100 \%$ of children qualify for reduced/free lunches).

231 Children listed 8,630 and 8,280 responses (up to four responses per student) for animals

232 they liked and thought were scary, respectively. After removing humans, "none," animals that

233 were not real, extinct animals, and responses we could not decipher, 8,477 responses of liked

234 animals and 8,049 of scary animals were useable for analyses. Of these freeform responses,

$23524.9 \%$ consisted of local animals, $43.3 \%$ exotic, and 31.5\% domestic. For the ranking question,

236 most children (67\%) ranked species according to the directions and incomplete responses or

237 incorrect ranks were removed.

238 Freeform responses

239 Collectively, in the freeform responses where children could write any animal they liked

240 or thought was scary, most children wrote mammals. The most frequently mentioned 
241 mammals, regardless of whether they were liked or thought of as scary, were dogs (16.0\%), cats

242 (8.2\%), pandas (5.6\%), rabbits (4.4\%), and wolves (3.8\%, Fig 1). For animals that children liked,

243 mammals were recorded nearly twice as often as other animal classes (82.5\%, Fig 2). Birds were

244 the second most frequently mentioned taxonomic class liked (5.8\% of listed animals), followed

245 by reptiles (5.2\%), fish (3.8\%), and terrestrial invertebrates (1.3\%; Fig 2).

246 Of the animals listed as liked, $44.4 \%$ were exotic, $43.5 \%$ were domestic, and only $12.1 \%$

247 were local. Suburban children listed the most exotic animals making up $46.04 \%$ of their

248 responses, and included a large percentage of domestic animals (41.7\%), but few local (12.22\%)

249 animals. Similarly, the responses of exurban and rural children consisted mostly of domestic

$250(44.8 \%$ and $53.48 \%)$ and exotic animals (43.8\% and $31.4 \%)$ with few local $(11.47 \%$ and $15.11 \%$,

251 Fig 3) animals. We allowed children to list up to four species they liked and on average

252 suburban children included 0.45 ( \pm 0.68 SD) local animals, exurban children listed $0.41( \pm 0.68$

253 SD), and rural children added 0.57 ( $\pm 0.86 \mathrm{SD}$ ) local species (Fig 4). A Fligner-Killeen test found

254 no significant differences among these groups of children in the variance in the proportion of

255 the animals that they listed that were local $\left(\chi^{2}=5.61, d f=2, p=0.06\right)$ and a Kruskal-Wallis test

256 found no significant differences across the means $\left(\chi^{2}=4.88, d f=2, p=0.09\right)$.

257 Mammals were also the dominant class for animals considered scary, but whereas

258 nearly all liked taxa were mammals, fewer than half of scary taxa were mammals (40.5\%, Fig 2).

259 Children listed terrestrial invertebrates as the second most scary class of animals (20.23\%),

260 followed by reptiles (19.7\%), fish (13.4\%), and marine invertebrates (2.02\%). Children listed

261 almost the same percentage of exotic animals as scary $(42.4 \%)$ that they listed as liked (44.4\%).

262 However, scary animals included far fewer domestic animals (19.1\%), and a higher percentage 
263 of local animals (38.5\%) than the liked species listed for animals children liked. In other words,

264 local, non-domesticated animals were more than three times as likely to be mentioned by

265 children as scary than as liked. When children were asked to free-list four scary animals, on

266 average, suburban children included $1.47( \pm 1.03)$ local animals, exurban children listed 1.42

267 ( \pm 0.99$)$, and rural children listed $1.32( \pm 0.91)$. A Fligner-Killeen test found no significant

268 differences across variances $\left(\chi^{2}=0.04, \mathrm{df}=2, \mathrm{p}=0.11\right)$ and a Kruskal-Wallis test found no

269 significant differences across the means $\left(\chi^{2}=2.61, d f=2, p=0.27\right)$.

270 Animal ranking results

271 Of the five animals ranked from the provided list of 20 , the most favorably were all

272 exotic (except for the rabbit); they included the panda, wolf, monkey, and lion (Fig 5). Animals

273 least often included in children's top five were almost all local animals including the opossum,

274 skunk, raccoon, and bat. The one exception was the rhinoceros, which was the only exotic

275 animal least often included in children's top five. On average, children included 1.94 ( \pm 1.04 SD)

276 local animals in their top five rankings with suburban children listing 1.93 ( \pm 1.01 SD) local

277 animals, exurban children listing 1.90 ( \pm 1.08 SD), and rural children listing 2.33 ( \pm 1.11 SD) local

278 animals. We found significant differences in variance $\left(\chi^{2}=7.85, \mathrm{df}=2, \mathrm{p}=0.02\right)$ using Fligner-

279 Killeen test and log transformed responses after adding one to perform a Kruskal-Wallis one-

280 way ANOVA. These results were also significant $\left(\chi^{2}=15.19, \mathrm{df}=2, \mathrm{p}<0.00\right)$ and a post-hoc Tukey

281 and Kramer (Nemenyi) test revealed significant differences between suburban and rural

$282(p=0.00)$, and rural and exurban areas $(p<0.00)$ in the average number of local animals ranked.

283 Rural children ranked the panda lower and had higher rankings of most local animals (Fig 5).

284 However, the Spearman rank correlation test found that the actual rankings of animals, the way 
285 the children ordered animals from most favorite to least, was significantly correlated among all

286 levels of urbanization (rural and suburban, $\mathrm{S}=222, \mathrm{p}<0.00, \rho=0.83$; rural and exurban, $\mathrm{S}=168$,

$287 \mathrm{p}<0.00, \rho=0.87$; and suburban and exurban, $\mathrm{S}=24, \mathrm{p}<0.00, \rho=0.98)$, suggesting that children

288 across rural, exurban, and suburban areas rank mammals similarly.

289 Model results

$290 \quad$ For animals that children liked, children who hunted included more local animals

$291(p=0.001)$, as did white children $(p=0.025)$, and children in sixth grade $(p=0.004$, Table 1$)$

292 compared to children that didn't hunt, were non-white, and enrolled in other grades. Female

293 children included fewer local animals $(p=0.000)$ than males for animals they liked. For scary

294 animals, female and white children recorded more local animals as scary compared to male

295 children and non-white children ( $p=0.002$ and 0.025 respectively). Only fourth grade children

296 listed fewer local animals as scary than did the other grades $(p=0.016$, Table 1$)$. When children

297 were asked to rank animals, children that hunted $(p=0.001)$ or those who were in grade six

298 ranked more local animals in their top five $(p=0.008$, Table 1$)$ than those who didn't hunt or

299 were in other grades.

300

301 Discussion

302 The similarity of children's categorization of animals across different levels of

303 urbanization suggests that the presumed higher levels of familiarity children in more rural areas

304 have with local wildlife is limited. While we did find that children in rural areas 'liked' more local

305 animals, and listed fewer local animals as scary, we also found that youth in exurban, and not

306 suburban areas, 'liked' the fewest local animals. However, these differences were marginal, and 
307 housing density was not found to be an important factor in the model results when we

308 controlled for student demographics. In short, children across all levels of urbanization viewed

309 wildlife in similar ways. We offer two possible explanations. First, children's exposure to local

310 wildlife species by living in more undeveloped areas may not necessarily translate to more

311 favorable wildlife perceptions or knowledge of local species. Our results may instead suggest

312 that other factors are important in shaping how children perceive wildlife, for instance, outdoor

313 recreation (James et al. 2010) and cultural norms (Pease 2011). Another possibility is that

314 despite the higher levels of undeveloped land found in rural versus suburban areas, children

315 may not be interacting with it. This latter explanation is supported by mounting evidence that

316 even the most rural children spend more and more time indoors (Larson et al. 2018).

In general, local animals made up a larger percentage of perceived scary animals, while

318 they rarely showed up for animals that students liked. This could reflect low knowledge of

319 native biodiversity, which was also found in a previous North Carolina study, in which children

320 listed their favorite animals in North Carolina and the world (Peterson et al. 2017). Of these,

$32187 \%$ of the global species were correctly identified as wildlife (e.g., non-pet), but only $60 \%$

322 were correctly identified as native (Peterson et al. 2017). In this study, students included a

323 higher percentage of local animals for those that they thought were scary, which suggested

324 that children were aware of and could recall local species. Children frequently listed snakes,

325 spiders, sharks, and bears as scary, and all of these taxa are found in North Carolina. However,

326 emergency room visits for dog bites, the most 'liked' animal in this study, were nearly seven

327 times greater than those for venomous snakes and spiders combined and four times more than

328 other uncategorized animals combined (Langley 2012). This mismatch between actual and 
329 perceived risk may be explained by negative portrayals of these types of wildlife in the media

330 (Muter et al. 2012; Peterson et al. 2010). Given the increase in screen time paired with the

331 decrease in time outdoors (Larson et al., 2018), it is plausible that children have infrequent

332 encounters with local wildlife, and experiences are primarily virtual.

333 The modestly higher numbers of local animals listed by rural children may have been

334 more heavily influenced by hunting rather than living in a rural area. Time spent outdoors

335 hunting can provide exposure to local biodiversity, increasing the number of animals students

336 could list and potentially dampen their fears of wildlife. Indeed, Peterson et al. (2017) found

337 hunting to be a positive predictor of biodiversity knowledge among children in North Carolina.

338 In our model, children who hunted or who had family members that hunted were more likely to

339 free list local animals for those that they liked and rank them more favorably. Furthermore,

340 rural children ranked deer, an important game species, as their most liked species, which may

341 be a result of the larger number of hunters among rural children. Fifty-five percent of rural

342 children hunted compared to $13.8 \%$ and $7.6 \%$ for exurban and suburban schools respectively.

343 Future research should measure time children spent outdoors and the types of activities

344 children engage in to better understand the mechanisms driving relationships between

345 children's exposure to diversity and perceptions of wildlife.

346 Despite the troubling trends observed with respect to children's unfamiliarity with local

347 wildlife, several encouraging results for conservation emerged. Of the top ten animals children

348 listed as 'liked', five included species or taxonomic groups with one or more species listed as

349 vulnerable or higher conservation status on the International Union for Conservation of Nature

350 and Natural Resources Red List (e.g. panda, wolf, monkey, dolphin, lion, and tiger). Charismatic, 
351 "flagship" species have become iconic for conservation, and while controversial, they have

352 increased positive attitudes towards species, and raised money for organizations (Dietz et al.

353 1994; Smith \& Sutton 2008). We also found that children listed higher percentages of wild

354 animals and fewer domestics in the free-listed questions than what has been observed in

355 previous studies (Bjerke et al. 1998; Lindemann-Matthies 2005), again suggesting the potential

356 influence of viewing exotic animals in zoos or in the media. This shift is encouraging, as

357 domestic cats and dogs contribute to native species declines (Doherty et al. 2017; Loss et al.

358 2013), and when native and domestic species are at odds, difficult measures such as the

359 euthanasia of domestic species are sometimes necessary. These methods are often unpalatable

360 to the public (Peterson et al. 2017; Tennent et al. 2010), and preferences shifting towards wild

361 animals may allow for greater understanding on such controversial management policies.

362 Model results revealed that efforts to connect children to nature should target girls and

363 non-white children as well as continuing to engage children as they grow older. That these

364 groups seemed to have particularly low familiarity with or view local animals as scary suggests

365 that they are candidates for efforts to ensure broad support for biodiversity conservation in a

366 local context. Similar trends have been found in other studies and calls to engage girls and

367 minorities have existed for decades (Foster et al. 2013; Lopez et al. 2011; Stevenson et al.

368 2017). Our results that younger students included more local animals as liked (sixth graders)

369 and fewer as scary (fourth graders) than other grade levels could be related to curriculum (e.g.,

370 both sixth and fourth grades have wildlife-related standards: NC Department of Public

371 Instruction, http://www.ncreportcards.org/src/). However, other studies find that connections

372 to nature and interest in the environment and wildlife decline as children age (Frew et al. 2016; 
373 Stevenson et al. 2013), suggesting that efforts should continue to find ways to engage with

374 older children. Finally, Caucasian children listed more local species for both liked and scary

375 animals, suggesting a higher level of familiarity with local wildlife. This also reflects previous

376 research, which finds that white children generally have higher environmental literacy levels

377 than minority children (Stevenson et al. 2013). This has been linked to cultural views of the

378 outdoors and the environment (Finney 2006; Johnson et al. 2004) and recreation patterns

379 (Floyd et al. 2009; Shores et al. 2007). As suggested by many (Lopez et al. 2011; Stevenson et al.

380 2017), our results support the need for culturally sensitive opportunities to engage diverse

381 constituents, including children, with local wildlife.

382 Although we offer these results as a contribution to conversations around the effects of

383 children's diminished exposure to nature, future research should continue to explore these

384 questions with larger and more diverse samples. In our study, rural children were the least

385 represented, and came from one rural school. While our model results found no school effect,

386 future studies with larger sample sizes and more schools are needed to confirm the patterns

387 observed in this study.

388

389 Conclusions

390 Our results imply that it may not be urbanization alone that is driving the Extinction of

391 Experience, as the disconnect with wildlife among children spans across areas of urbanization.

392 As conservation biologists, we are encouraged by the large percentage of globally endangered

393 animals included for animals children liked, but find the low knowledge and unfavorable

394 attitudes towards local species troubling. 

children just noticing native plants and animals on the way to school increased their appreciation of and concern for local species' well-being. Species-targeted programs have even increased children's attitudes towards "unlikeable" species (Ballouard et al. 2012; Tomazic 2011). A particularly impactful way of increasing exposure to native wildlife may be through nature-based citizen science programs, where active participation in research encourages observations about the environment, increasing participants' knowledge on local biodiversity.

403 Future studies should focus on understanding the role of such intentional activities in 404 connecting children to nature, and design and evaluate culturally responsive ways of doing so.

405 As the disconnect between children and wildlife is perhaps even more pronounced than

406 previously understood, intentionally providing children experiences in nature may be one of the

407 most important actions conservation biologists can take to promote biodiversity conservation 408 among and for future generations.

\section{Acknowledgements}

412 We would like to thank the teachers and school districts for allowing us to implement surveys in

413 their schools. We also thank Mariah Patton, Rebecca Spears, Spencer Stone, Colleen Lippert,

414 Caitlyn Mothes, and Kristen Lewey for help in survey data organization.

\section{References}


416 Aronson MFJ, La Sorte FA, Nilon CH, Katti M, Goddard MA, Lepczyk CA, Warren PS, Williams

417

418

419

420

421

422

423

424

425

426

427

428

430

431

432

433

435

436

437
NSG, Cilliers S, Clarkson B, Dobbs C, Dolan R, Hedblom M, Klotz S, Kooijmans JL, Kühn I, MacGregor-Fors I, McDonnell M, Mörtberg U, Pyšek P, Siebert S, Sushinsky J, Werner P, and Winter M. 2014. A global analysis of the impacts of urbanization on bird and plant diversity reveals key anthropogenic drivers. Proceedings of the Royal Society B: Biological Sciences 281.

Ballouard J-M, Brischoux F, and Bonnet X. 2011. Children prioritize virtual exotic biodiversity over local biodiversity. PLOS ONE 6:e23152.

Ballouard J-M, Provost G, Barré D, and Bonnet X. 2012. Influence of a field trip on the attitude of schoolchildren toward unpopular organisms: An experience with snakes. Journal of Herpetology 46:423-428.

Balmford A, Clegg L, Coulson T, and Taylor J. 2002. Why conservationists should heed Pokémon. Science 295:2367.

Bixler RD, and Floyd MF. 1997. Nature is scary, disgusting, and uncomfortable. Environment and Behavior 29:443-467.

Bjerke T, $\varnothing$ degårdstuen TS, and Kaltenborn BP. 1998. Attitudes toward animals among Norwegian children and adolescents: Species preferences. Anthrozoös 11:227-235.

Borgi M, and Cirulli F. 2015. Attitudes toward animals among kindergarten children: Species preferences. Anthrozoös 28:45-59.

Brook A, Zint M, and De Young R. 2003. Landowners' responses to an Endangered Species Act listing and implications for encouraging conservation. Conservation Biology 17:16381649. 
438 Burnham KP, and Anderson DR. 2002. Model selection and multimodel inference: a practical information-theoretic approach. New York, New York, U.S.A.: Springer-Verlag Inc.

440 Dietz JM, Dietz LA, and Nagagata EY. 1994. The effective use of ${ }^{-}$flagship species for conservation of biodiversity: the example of lion tamarins in Brazil. In: Olney PJS, Mace GM, and Feistner ATC, eds. Creative Conservation: Interactive Managment of Wild and Captive Animals. London, 32-49.

Dirzo R, Young HS, Galetti M, Ceballos G, Isaac NJB, and Collen B. 2014. Defaunation in the Anthropocene. Science 345:401.

Doherty TS, Dickman CR, Glen AS, Newsome TM, Nimmo DG, Ritchie EG, Vanak AT, and Wirsing AJ. 2017. The global impacts of domestic dogs on threatened vertebrates. Biological Conservation 210, Part A:56-59.

Dunn RR, Gavin MC, Monica CS, and Jennifer NS. 2006. The pigeon paradox: Dependence of global conservation on urban nature. Conservation Biology 20:1814-1816.

Feinsinger P. 1987. Professional ecologists and the education of young children. Trends in Ecology \& Evolution 2:51-52.

Finney C. 2006. Black faces, white spaces: African-Americans and the great outdoors. Worcester, MA: Clark University: Report to USA Community Forestry Research

Floyd MF, Taylor WC, and Whitt-Glover M. 2009. Measurement of park and recreation environments that support physical activity in low-income communities of color: Highlights of challenges and recommendations. American Journal of Preventive Medicine 36:S156-S160. 
460 Foster MJ, Blair ME, Bennett C, Bynum N, and Sterling EJ. 2013. Increasing the diversity of U.S.

461 Conservation Science Professionals via the Society for Conservation Biology.

462 Conservation Biology 28:288-291.

463 Frew K, Peterson MN, and Stevenson K. 2016. Are we working to save the species our children 464 want to protect? Evaluating species attribute preferences among children. Oryx 51:455465463.

466 Genovart M, Tavecchia G, Enseñat JJ, and Laiolo P. 2013. Holding up a mirror to the society: 467 Children recognize exotic species much more than local ones. Biological Conservation $468 \quad 159: 484-489$.

469 Hammer RB, Stewart SI, Winkler RL, Radeloff VC, and Voss PR. 2004. Characterizing dynamic spatial and temporal residential density patterns from 1940-1990 across the North Central United States. Landscape and Urban Planning 69:183-199.

Inskip C, and Zimmermann A. 2009. Human-felid conflict: a review of patterns and priorities worldwide. Oryx 43:18-34.

James JJ, Bixler RD, and Vadala CE. 2010. From play in nature to recreation, then vocation: A developmental model for natural history oriented environmental professionals. Children, Youth, and Environments 20:231-256. behavior: An examination of the new ecological paradigm in a social psychological context. Environment and Behavior 36:157-186. 
480 Kellert SR, Case DJ, Escher D, Witter DJ, Mikels-Carrasco J, and Seng PT. 2017. The nature of $481 \quad$ Americans: Disconnection and recommendations for reconnection. Mishawaka, IN. p 1362.

483 Langley RL. 2012. Animal-related injuries resulting in emergency department visits and 484 hospitalizations in the United States, 2006-2008. Human-Wildlife Interactions 6.

Larson LR, Szczytko R, Bowers EP, Stephens LE, Stevenson KT, and Floyd MF. 2018. Outdoor time, screen time, and connection to nature: Troubling trends among rural youth? Environment and Behavior:1-26.

Lindemann-Matthies P. 2005. 'Loveable' mammals and 'lifeless' plants: how children's interest in common local organisms can be enhanced through observation of nature. International Journal of Science Education 27:655-677.

Lopez R, Brown C, and Unger BK. 2011. How workforce diversity helps conservation. Wildlife Professional 5:20-27.

Loss SR, Will T, and Marra PP. 2013. The impact of free-ranging domestic cats on wildlife of the United States. Nature Communications 4:1396.

Manfredo MJ, Bruskotter JT, Teel TL, Fulton D, Schwartz SH, Arlinghaus R, Oishi S, Uskul AK, Redford K, Kitayama S, and Sullivan L. 2017. Why social values cannot be changed for the sake of conservation. Conservation Biology 31:772-780.

McKinney ML. 2008. Effects of urbanization on species richness: A review of plants and animals. Urban Ecosystems 11:161-176.

500 Meuser E, Harshaw HW, and Mooers AØ. 2009. Public preference for endemism over other conservation-related species attributes. Conservation Biology 23:1041-1046. 
502 Milligan C, and Bingley A. 2007. Restorative places or scary spaces? The impact of woodland on 503 the mental well-being of young adults. Health \& Place 13:799-811.

504 Muter BA, Gore ML, Gledhill KS, Lamont C, and Huveneers C. 2012. Australian and U.S. news media portrayal of sharks and their conservation. Conservation Biology 27:187-196.

Pease JL. 2011. Parks and underserved audiences: An annotated literature review. Journal of Interpretation Research 20:11-56.

Peterson MN, Birckhead JL, Leong K, Peterson MJ, and Peterson TR. 2010. Rearticulating the myth of human-wildlife conflict. Conservation Letters 3:74-82.

Peterson MN, Chesonis T, Stevenson KT, and Bondell HD. 2017. Evaluating relationships between hunting and biodiversity knowledge among children. Wildlife Society Bulletin 41:530-536.

513 Pyle RM. 1978. The extinction of experience. Horticulture 56:64-67.

514 Schlegel J, and Rupf R. 2010. Attitudes towards potential animal flagship species in nature conservation: A survey among students of different educational institutions. Journal for Nature Conservation 18:278-290.

517 Schuttler SG, Glenn D, Belair C, Hohm J, Humphries D, Pasion D, Dunn RR, and Kays R. 2017. scientific investigations. Science Scope 41:63-71.

Schuttler SG, Sears RS, Orendain I, Khot R, Rubenstein D, Rubenstein N, Dunn RR, Baird E, Kandros K, O'Brien T, and Kays R. 2018. Citizen science in schools: Students collect valuable mammal data for science, conservation, and community engagement. Bioscience:biy141-biy141. 
524 Shores KA, Scott D, and Floyd MF. 2007. Constraints to outdoor recreation: A multiple hierarchy 525 stratification perspective. Leisure Sciences 29:227-246.

526

527

528

\section{Figure Legends}

Table 1. Summary table of the covariates included in the three models, their estimates, and p-

544 values for animals children liked, thought were scary, and ranked from a list. *indicates $p \leq$ 
$5450.05, * * p \leq 0.005, * * * p \leq 0.0005$, na refers to covariates not included in the top final models,

546 and ref are covariates used as a reference level.

547 Table 2. Sample sizes of children's responses by covariate categories. SES is socioeconomic

548 status. Sample sizes vary across questions because not all children answered all questions or

549 answered questions incorrectly (as in the ranking question).

550 Fig 1. Free list responses of children listing animals they liked or thought were scary. Light gray

551 bars show the number of responses for 'liked' animals and black represent listing as 'scary'.

552 Fig 2. Classification of animals (modifications noted in text) free listed by children as 'liked' or

553 'scary'. Only responses with 50 or more counts are included. Light gray bars show the

554 proportion of responses for 'liked' animals and black bars represent listing as 'scary'.

555 Fig 3. Percent of local, exotic, and domestic animal animals children free listed as liked or scary.

556 Light gray bars show the number of responses for 'liked' animals and black bars represent

557 listing as 'scary'.

558 Fig 4. Percent of 'liked' animals that were local, exotic, and domestic grouped by the school

559 location in either a suburban, exurban, and rural areas.

560 Fig 5. The mean ranking of each animal in a provided list of 20 by children across different levels

561 of urbanization. Higher scores indicate the ranking of animals more favorably. Error bars

562 represent standard deviation of the mean. 
Figure 1

Free list responses of children listing animals they liked or thought were scary. Light gray bars show the number of responses for 'liked' animals and black represent listing as 'scary'. 


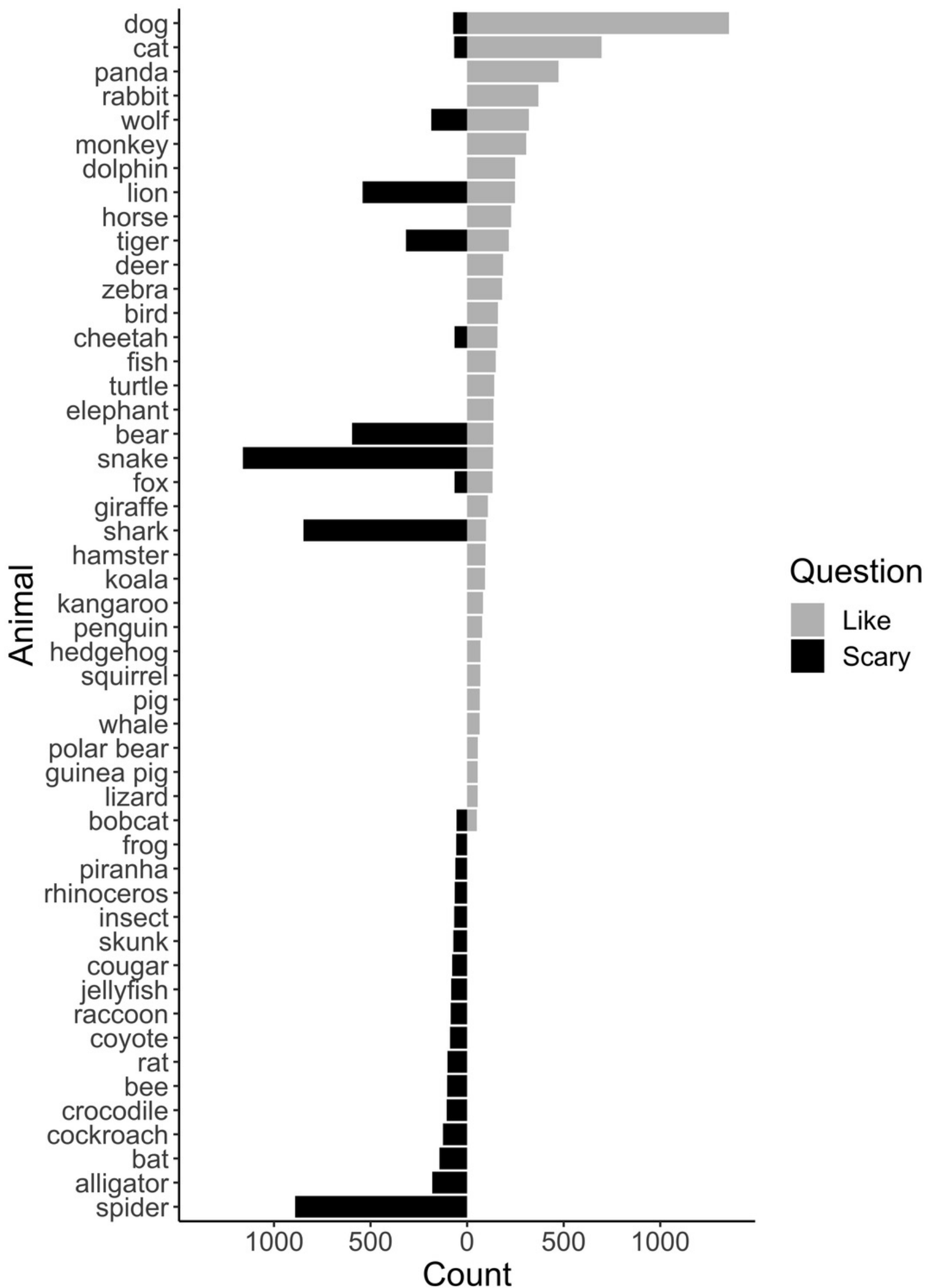




\section{Figure 2}

Classification of animals (modifications noted in text) free listed by children as 'liked' or 'scary'. Only responses with 50 or more counts are included.

Light gray bars show the proportion of responses for 'liked' animals and black bars represent listing as 'scary'.

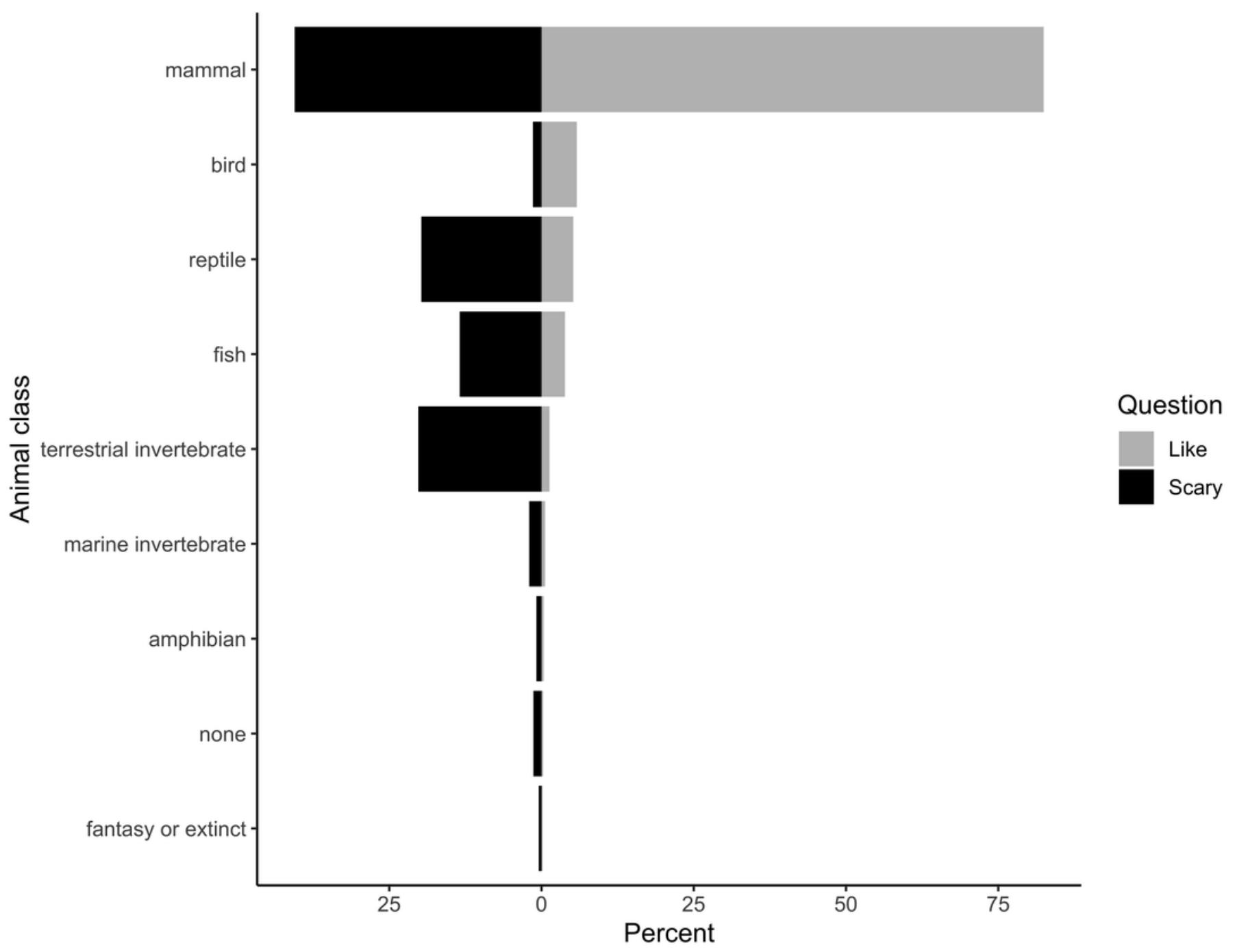




\section{Figure 3}

Percent of local, exotic, and domestic animal animals children free listed as liked or scary.

Light gray bars show the number of responses for 'liked' animals and black bars represent listing as 'scary'.

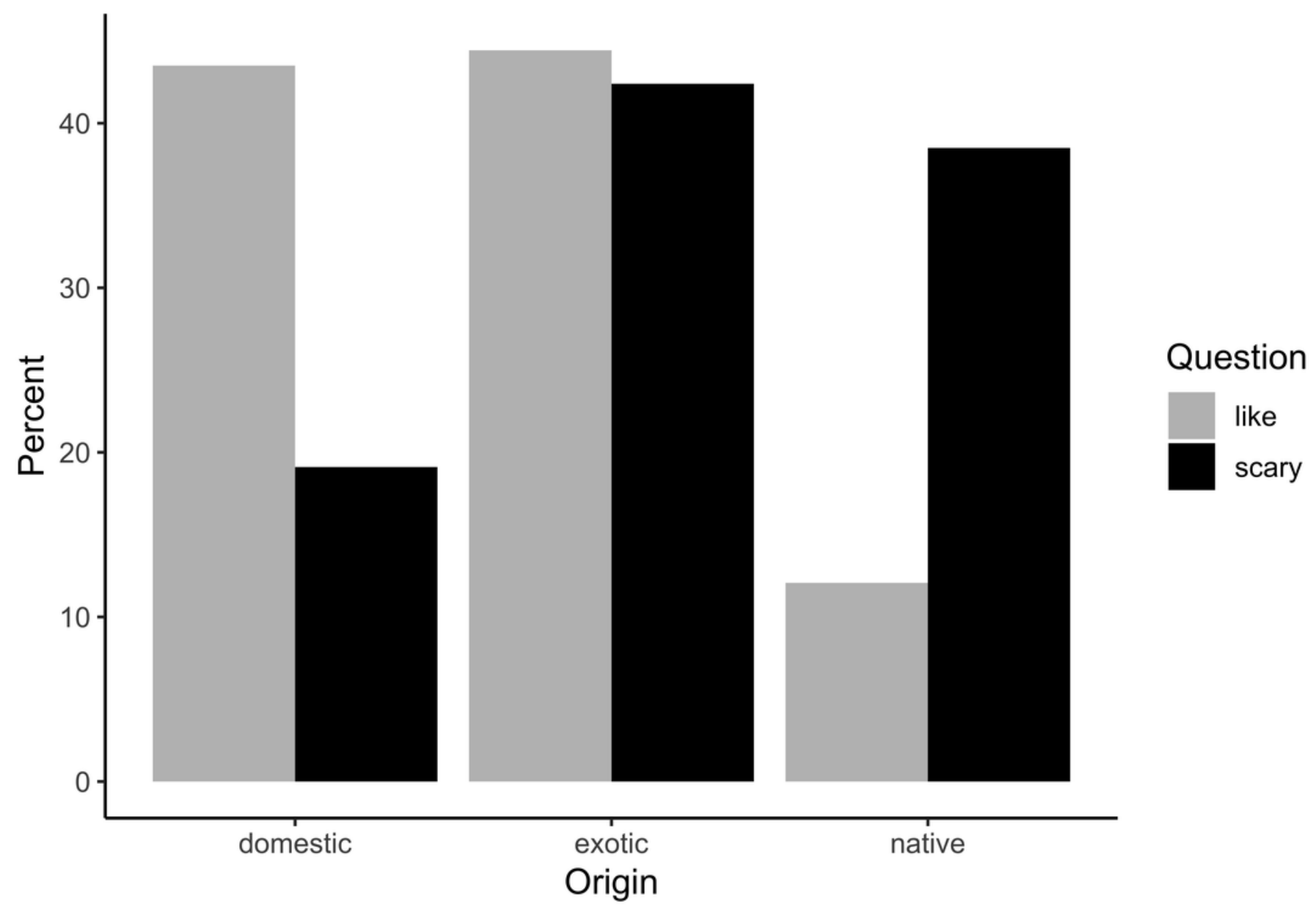




\section{Figure 4}

Percent of 'liked' animals that were local, exotic, and domestic grouped by the school location in either a suburban, exurban, and rural areas.

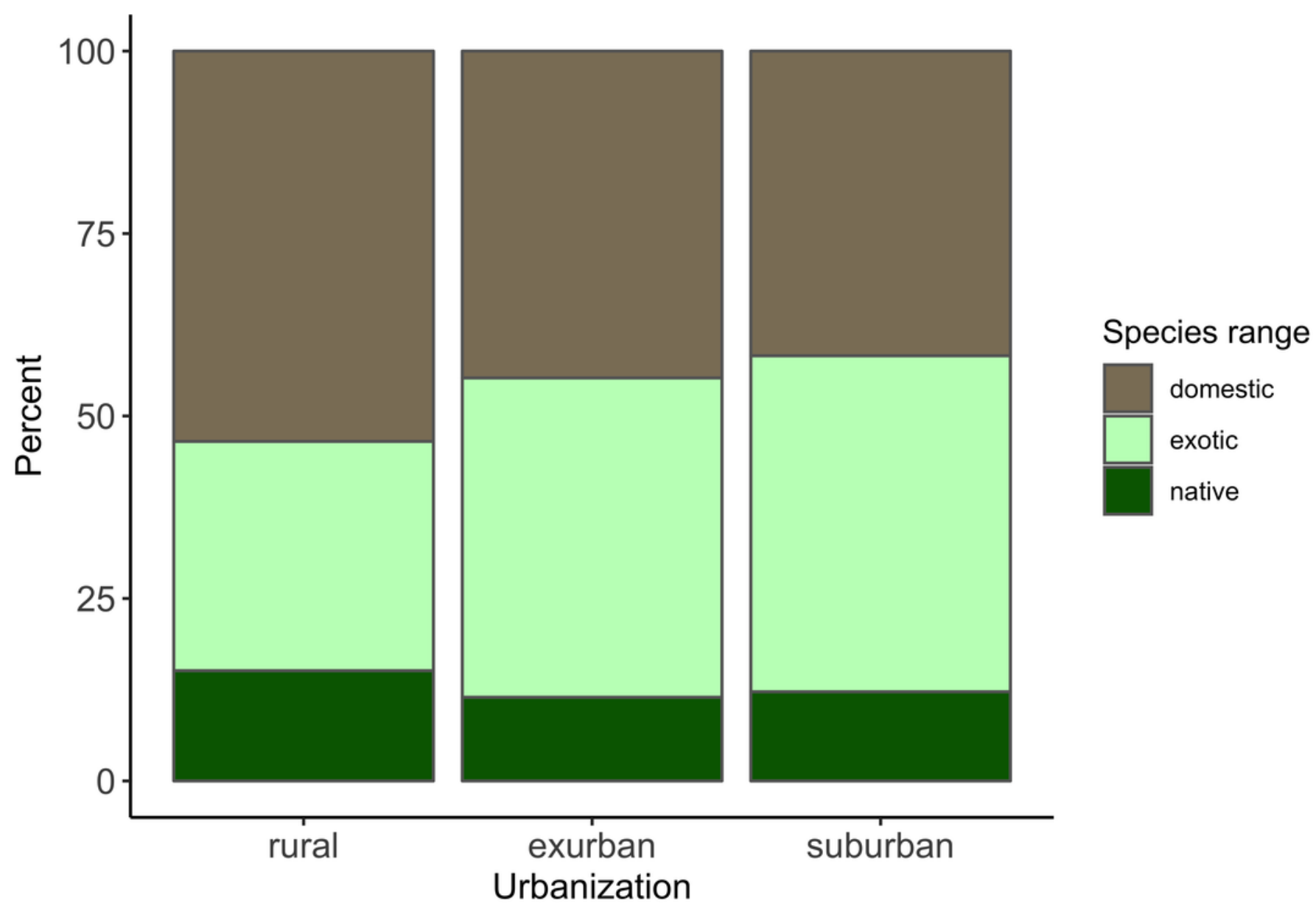




\section{Figure 5}

The mean ranking of each animal in a provided list of 20 by children across different levels of urbanization.

Higher scores indicate the ranking of animals more favorably. Error bars represent standard deviation of the mean.

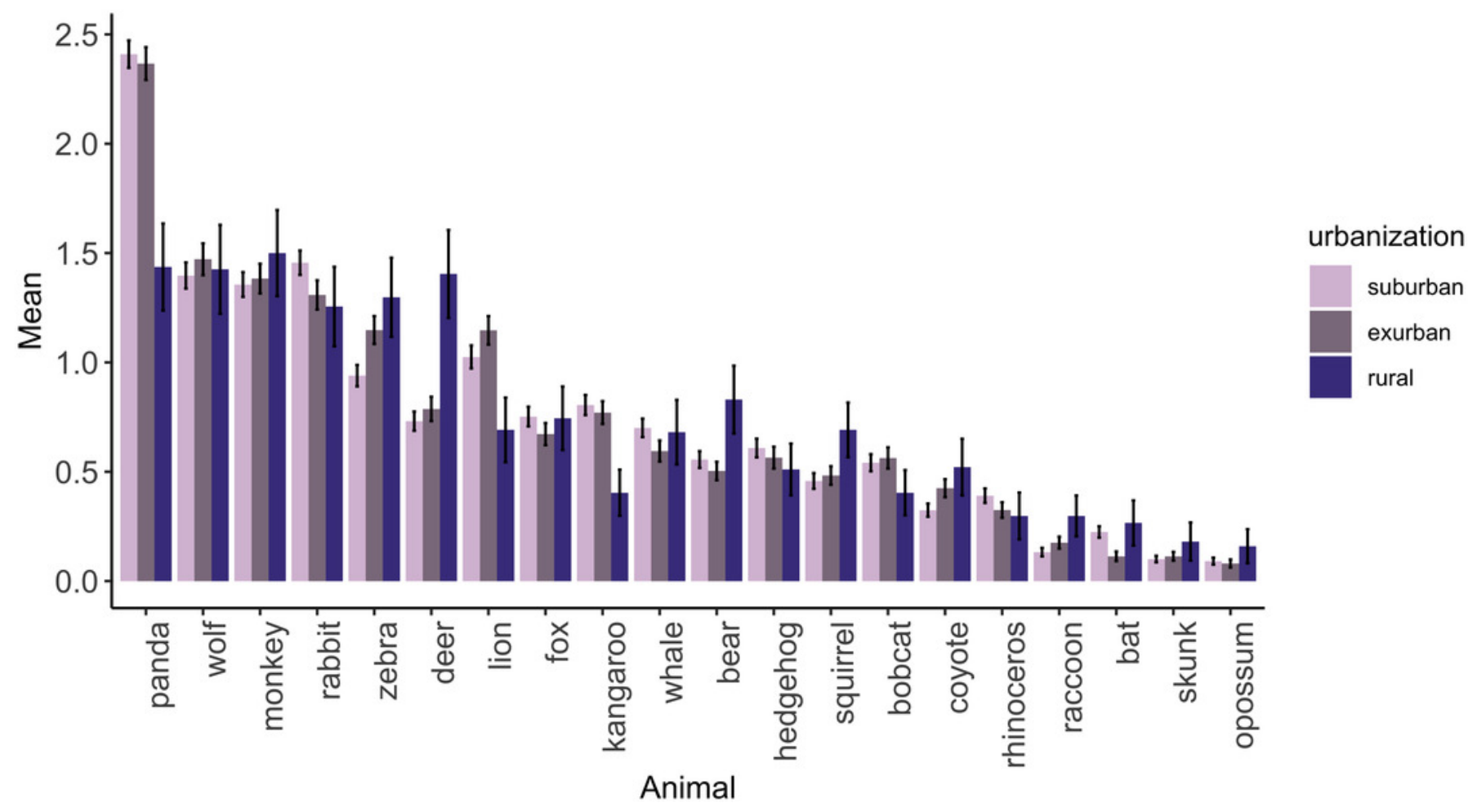




\section{Table $\mathbf{1}$ (on next page)}

Summary table of the covariates included in the three models, their estimates, and $\mathrm{p}$ values for animals students liked, thought were scary, and ranked from a list.

$*$ indicates $p \leq 0.05,{ }^{* *} p \leq 0.005, * * p \leq 0.0005$, na refers to covariates not included in the top final models, and ref are covariates used as a reference level. 
1 Table 1. Summary table of the covariates included in the three models, their estimates, and p-

2 values for animals students liked, thought were scary, and ranked from a list. *indicates $p \leq$

$30.05, * * p \leq 0.005, * * * p \leq 0.0005$, na refers to covariates not included in the top final models,

4 and ref are covariates used as a reference level.

5

\begin{tabular}{lllll} 
Variable & Liked animals & Scary animals & Ranked animals \\
\hline Estimate $p$ & Estimate $p$ & Estimate $p$
\end{tabular}

\section{Gender}

Male ref ref ref ref ref ref

Female $\quad-0.400 * * * \quad 0.000 \quad 0.116^{* *} \quad 0.002 \quad-0.044 \quad 0.194$

Grade

$\begin{array}{lllllll}\text { Grade } 4 & -0.946 & 0.108 & -0.621^{*} & 0.016 & 0.018 & 0.928\end{array}$

$\begin{array}{lllllll}\text { Grade } 6 & 0.230 * * & 0.004 & -0.043 & 0.347 & 0.113 * * & 0.008\end{array}$

$\begin{array}{lllllll}\text { Grade } 7 & 0.065 & 0.505 & -0.078 & 0.142 & 0.050 & 0.312\end{array}$

Grade 8 ref ref ref ref ref ref

Race

$\begin{array}{lllllll}\text { White } & 0.154 * & 0.025 & 0.086 * & 0.025 & 0.062 & 0.081\end{array}$

Non-white ref ref ref ref ref ref

Hunting

$\begin{array}{lllllll}\text { Hunter } & 0.330 * * * & 0.001 & 0.081 & 0.166 & 0.182^{* * *} & 0.001 \\ \text { Not a hunter ref } & \text { ref } & \text { ref } & \text { ref } & \text { ref } & \text { ref } \\ \text { No response } & 0.044 & 0.560 & 0.007 & 0.865 & 0.001 & 0.967\end{array}$


on hunting

$\begin{array}{lllllll}\text { Housing } & 0.000 & 0.276 & 0.000 & 0.082 & 0.000 & 0.255 \\ \text { Density } & & & & & & \\ \text { Proportion } & -0.044 & 0.806 & -0.062 & 0.541 & 0.104 & 0.253 \\ \text { of free and } & & & & & & \\ \text { reduced }\end{array}$




\section{Table 2 (on next page)}

Sample sizes of students' responses by covariate categories.

SES is socioeconomic status. Sample sizes vary across questions because not all students answered all questions or answered questions incorrectly (as in the ranking question). 
1 Table 2. Sample sizes of students' responses by covariate categories. SES is socioeconomic status. Sample sizes vary across questions

2 because not all students answered all questions or answered questions incorrectly (as in the ranking question).

\begin{tabular}{llllllllll} 
& \multicolumn{2}{l}{ Liked Animals } & \multicolumn{3}{c}{ Scary Animals } & \multicolumn{2}{c}{ Ranked Animals } \\
& Suburban & Exurban & Rural & Suburban & Exurban & Rural & Suburban & Exurban & Rural \\
\hline Total & 1209 & 862 & 105 & 1183 & 854 & 107 & 1032 & 707 & 93 \\
Male & 584 & 397 & 52 & 571 & 390 & 56 & 495 & 325 & 49 \\
Female & 616 & 452 & 52 & 603 & 452 & 50 & 537 & 382 & 44 \\
Grade 4 & 20 & 0 & 0 & 20 & 0 & 0 & 15 & 0 & 0 \\
Grade 6 & 239 & 344 & 0 & 236 & 356 & 0 & 193 & 259 & 0 \\
Grade 7 & 290 & 0 & 105 & 289 & 0 & 107 & 252 & 0 & 93 \\
Grade 8 & 660 & 517 & 0 & 638 & 498 & 0 & 572 & 447 & 0 \\
White & 532 & 360 & 62 & 526 & 361 & 61 & 479 & 326 & 60 \\
Non-white & 677 & 502 & 43 & 649 & 482 & 46 & 553 & 381 & 33 \\
Hunter & 93 & 123 & 58 & 91 & 126 & 58 & 78 & 100 & 52
\end{tabular}


No response

on hunting

420

444

$0 \quad 400$

425

0

359

367 